\title{
POLÍTICAS E GESTÃO DA EDUCAÇÃO BÁSICA NO BRASIL: LIMITES E PERSPECTIVAS
}

\author{
Luiz Fernandes Dourado*
}

RESUMO: O presente artigo aborda o cenário político e pedagógico em que se realizam as políticas direcionadas à gestão da educação básica, buscando explicitar concepçôes, açôes e programas governamentais, bem como suas interfaces com a suposta qualidade preconizada para esse nível de ensino no Brasil. Nesta perspectiva, ao analisar tais políticas e programas no contexto de reforma do Estado, indica os limites e perspectivas desse processo, sob a ótica da construção de novos parâmetros para a qualidade e gestão democrática da escola pública.

Palavras-chave: Política educacional. Gestão educacional. Descentralização. Democratização.

\section{Policies For AND MANAGEMENT OF BASIC EDUCATION IN BRAZIL: LIMITS AND PERSPECTIVES}

ABSTRACT: This paper approaches the political and pedagogical scenario in which the policies directed to manage basic education take place. It seeks to explicit the government's conceptions, actions and programs and their interfaces with the supposed quality advocated for this teaching level in Brazil. When analyzing these policies and programs in the context of the reform of the State, it thus points out the limits and perspectives of this process in order to allow building new parameters for the quality and democratic management of public school.

Key words: Educational policies. Educational management. Decentralization. Democratization.

Doutor em Educação e professor titular da Faculdade de Educação da Universidade Federal de Goiás (UFG).E-mail: douradol@terra.com.br 


\section{Introdução}

7 discussão sobre políticas e gestão da educação tem sido objeto de vários estudos e pesquisas no cenário nacional ${ }^{1} \mathrm{e}$ internacional. ${ }^{2}$ Trata-se de temática com várias perspectivas, concepções e cenários complexos em disputa. Nesse sentido, é fundamental destacar a ação política, orgânica ou não, de diferentes atores e contextos institucionais marcadamente influenciados por marcos regulatórios fruto de orientaçoes, compromissos e perspectivas - em escala nacional e mundial -, preconizados, entre outros, por agências e/ou organismos multilateriais e fortemente assimilados e/ou naturalizados pelos gestores de políticas públicas.

Nessa ótica, a discussão sobre tais políticas articula-se a processos mais amplos do que a dinâmica intra-escolar, sem negligenciar, nesse percurso, a real importância do papel social da escola e dos processos relativos à organização, cultura e gestão intrínsecos a ela. Portanto, é fundamental não perder de vista que o processo educativo é mediado pelo contexto sociocultural, pelas condiçôes em que se efetiva o ensino-aprendizagem, pelos aspectos organizacionais e, consequentemente, pela dinâmica com que se constrói o projeto político-pedagógico e se materializam os processos de organização e gestão da educação básica.

Assim, a análise da gestão educacional pode se realizar por meio de vários recortes e planos. Uma perspectiva importante implica não reduzir a análise das políticas e da gestão educacional à mera descrição dos seus processos de concepção e/ou de execução, importando, sobremaneira, apreendê-las no âmbito das relaçôes sociais em que se forjam as condições para sua proposição e materialidade. Tal perspectiva implica detectar os tipos de regulação subjacentes a esse processo. Segundo Barroso (2006a, p. 13), o conceito de regulação, em que pesem os diferentes significados possíveis, pode ser utilizado "para descrever dois tipos diferenciados de fenômeno, mas interdependentes: os modos como são produzidas e aplicadas as regras que orientam a ação dos atores; os modos como esses mesmos atores se apropriam delas e as transformam".

Para efeito dessa análise, e considerando a especificidade do sistema educacional brasileiro, buscar-se-á apreender as concepçôes político-pedagógicas que norteiam a ação do governo federal no tocante à 
proposição de ações e programas implementados, visando à materialização das políticas na área, sem perder de vista que várias outras mediações interferem nesse processo.

O presente texto busca, portanto, situar as políticas direcionadas à gestão da educação básica por meio da análise da proposição de ações, programas e estratégias articulados pelo governo federal. Trata-se, portanto, de buscar apreender, no feixe dessas proposições, os limites e possibilidades à gestão das políticas (dada a situação nacional, em que estados e municípios se colocam como principais atores na oferta da educação básica no país), de modo a propiciar elementos para a compreensão dos processos de regulação e financiamento, bem como os arranjos institucionais que contribuem para a materialidade das políticas de gestão e organização educacionais no Brasil. Não se objetiva, portanto, discutir pormenorizadamente os programas e, sim, a lógica presente na proposição e os limites interpostos à sua materialização no âmbito dos sistemas de ensino, especialmente no que concerne aos diferentes pressupostos que norteiam os programas: Plano de Desenvolvimento da Escola, Programa Dinheiro Direto na Escola e Programa Nacional de Fortalecimento de Conselhos Escolares.

\section{A gestão como objeto de investigação e ação política}

No contexto nacional, a discussão sobre a gestão da educação básica apresenta-se a partir de várias proposições, bem como concepções e cenários complexos, articulados aos sistemas de ensino. Nessa direção, é fundamental situar os eixos que permeiam a presente análise sobre gestão, no tocante à concepção, formação e financiamento da educação.

A concepção de educação é entendida, aqui, como prática social, portanto, constitutiva e constituinte das relaçôes sociais mais amplas, ${ }^{3}$ a partir de embates e processos em disputa que traduzem distintas concepçôes de homem, mundo e sociedade. Para efeito desta análise, a educação é entendida como processo amplo de socialização da cultura, historicamente produzida pelo homem, e a escola, como lócus privilegiado de produção e apropriação do saber, cujas políticas, gestão e processos se organizam, coletivamente ou não, em prol dos objetivos de formação. Sendo assim, políticas educacionais efetivamente implicam o 
envolvimento e o comprometimento de diferentes atores, incluindo gestores e professores vinculados aos diferentes sistemas de ensino.

Dessa forma, a gestão educacional tem natureza e características próprias, ou seja, tem escopo mais amplo do que a mera aplicação dos métodos, técnicas e princípios da administração empresarial, devido à sua especificidade e aos fins a serem alcançados. ${ }^{4}$ Ou seja, a escola, entendida como instituição social, tem sua lógica organizativa e suas finalidades demarcadas pelos fins político-pedagógicos que extrapolam o horizonte custo-benefício stricto sensu. Isto tem impacto direto no que se entende por planejamento e desenvolvimento da educação e da escola e, nessa perspectiva, implica aprofundamento sobre a natureza das instituições educativas e suas finalidades, bem como as prioridades institucionais, os processos de participação e decisão, em âmbito nacional, nos sistemas de ensino e nas escolas.

Nessa perspectiva, a articulação e a rediscussão de diferentes açóes e programas, direcionados à gestáo educacional, devem ter por norte uma concepção ampla de gestão que considere a centralidade das políticas educacionais e dos projetos pedagógicos das escolas, bem como a implementação de processos de participação e decisão nessas instâncias, balizados pelo resgate do direito social à educação e à escola, pela implementação da autonomia nesses espaços sociais e, ainda, pela efetiva articulação com os projetos de gestão do MEC, das secretarias, com os projetos político-pedagógicos das escolas e com o amplo envolvimento da sociedade civil organizada.

Por outro lado, a problematização das condições de formação e profissionalização docentes ${ }^{5}$ coloca-se como questão interligada à gestão educacional e, nesse sentido, deve considerar os diferentes fatores que interferem na atuação dos profissionais da educação, bem como possibilitar o acesso a processos formativos que não descurem de uma base sólida de formação, não se reduzindo à disseminação de metodologias e estratégias de aprendizagem.

Rever a formação pedagógica requer, portanto, a articulação entre as políticas educacionais e as concepções de formação enquanto processos de construção coletiva. Implica, também, resgatar as experiências implementadas por estados e municípios como passos importantes no fortalecimento das açōes do MEC, em apoio às políticas de formação de professores e aos processos de organização, gestão educacional 
e escolar. Nesse sentido situam-se também as ações voltadas à organização da educação nacional, cujo norte político-pedagógico, no campo e na cidade, deve considerar a riqueza e a diversidade de experiências e as condiçõos e especificidades com as quais se realizam processos formativos para professores e estudantes, considerando a garantia de parâmetros de qualidade e indicando alternativas e perspectivas pedagógicas centradas em uma sólida concepção de educação, escola, cultura e gestão educacional.

Ao mesmo tempo, deve-se considerar o papel basilar das políticas de financiamento e regulação da educação, uma vez que os processos de gestão educacional e escolar são fortemente induzidos pela lógica decorrente do financiamento adotado, resultante da caracterização do Estado e da articulação entre as esferas pública e privada. Segundo Dourado (2006d, p. 282-283), para compreender

(...) o embate entre o público e o privado, é necessário ressaltar que os seus desdobramentos efetivos se vinculam a determinações estruturais de uma dada realidade, indicando, assim, a configuração assumida pelo Estado, o seu alcance jurídico-político-ideológico e as instituiçôes que o compõem (...). O embate entre o público e o privado, no campo educacional, revela a persistência de forças patrimoniais na educação, favorecendo, dessa forma, várias modalidades de privatização do público.

Tais indicadores situam a gestão educacional margeada por fatores intra e extra-escolares. Assim, a democratização dos processos de organização e gestão deve considerar as especificidades dos sistemas de ensino, bem como os graus progressivos de autonomia das unidades escolares a eles vinculados, e buscar a participação da sociedade civil organizada, especialmente o envolvimento de trabalhadores em educação, estudantes e pais.

Políticas e gestão da educação básica no Brasil: descontinuidade e centralização

A constituição e a trajetória histórica das políticas educacionais no Brasil, em especial os processos de organização e gestão da educação básica nacional, têm sido marcadas hegemonicamente pela lógica da descontinuidade, por carência de planejamento de longo prazo que evidenciasse políticas de Estado em detrimento de políticas 
conjunturais de governo. Tal dinâmica tem favorecido ações sem a devida articulação com os sistemas de ensino, destacando-se, particularmente, gestão e organização, formação inicial e continuada, estrutura curricular, processos de participação.

Desde a redemocratização do país, houve mudanças acentuadas na educação brasileira, com destaque para a aprovação e promulgação da Constituição Federal de 1988, que garantiu uma concepção ampla de educação e sua inscrição como direito social inalienável, bem como a partilha de responsabilidade entre os entes federados e a vinculação constitucional de recursos para a educação. No âmbito das políticas educacionais, destacaram-se, sobremaneira, as modificações de ordem jurídico-institucional. ${ }^{6}$

Nesse contexto, é fundamental ressaltar a busca de organicidade das políticas, sobretudo no âmbito do governo federal e de alguns governos estaduais, na década de 1990, quando, em consonância com a reforma do Estado e a busca de sua "modernização", se implementaram novos modelos de gestão, cujo norte político-ideológico objetivava, segundo Oliveira (2000, p. 331), “(...) introjetar na esfera pública as noções de eficiência, produtividade e racionalidade inerentes à lógica capitalista”. No campo educacional, há que se destacar, ainda, o importante papel desempenhado pelos organismos multilaterais na formulação de políticas educacionais no período.

Tais constataçôes evidenciam limites estruturais à lógica político-pedagógica dos processos de proposição e materialização das políticas educacionais, configurando-se, desse modo, em claro indicador de gestão centralizada e de pouca eficácia pedagógica para mudanças substantivas nos sistemas de ensino, ainda que provoque alterações de rotina, ajustes e pequenas adequações no cotidiano escolar, o que pode acarretar a suspensão de açôes consolidadas na prática escolar sem a efetiva incorporação de novos formatos de organização e gestão. Isto não redundou em mudança e, sim, em um cenário de hibridismo no plano das concepçóes e das práticas que, historicamente, no Brasil, têm resultado em realidade educacional excludente e seletiva. Vivencia-se, no país, um conjunto de ações, de modo parcial ou pouco efetivo, sob a ótica da mudança educacional, mas que, de maneira geral, contribui para desestabilizar o instituído, sem a força política de instaurar novos parâmetros orgânicos à prática educativa. 
Nessa direção, houve um conjunto de políticas de reestruturação da gestão, organização e financiamento da educação básica. Segundo Cury (2002, p. 197), nos dois mandatos de Fernando Henrique Cardoso (1995-1998; 1999-2002) promoveram-se diversas alterações fortemente marcadas

(...) por políticas focalizadoras, com especial atenção ao ensino fundamental, a fim de selecionar e destinar os recursos para metas e objetivos considerados urgentes e necessários. Tais políticas vieram justificadas por um sentido, por vezes satisfatório, do princípio da equidade como se este fosse substituto do da igualdade.

Desse quadro, é possível depreender que as políticas focalizadas propiciaram a emergência de programas e ações orientados pelo governo federal aos estados e municípios, destacando-se: a disseminação de Parâmetros Curriculares Nacionais (PCN), a implantação do Plano de Desenvolvimento da Escola (PDE) pelo FUndescola, a criação do Programa Dinheiro Direto na Escola (PDDE) e a implementação de uma política de avaliação fortemente centralizada, em detrimento de um sistema que propiciasse a colaboração recíproca entre os entes federados. A rapidez com que se processaram as políticas para a educação básica se deu em função da centralização no âmbito federal. Segundo Cury (2002, p. 199), sem a elaboração de lei complementar que defina o que é regime de colaboração entre os entes federados, prevista no $\$$ único do artigo 23, da CF/88, o país vivencia tensões no tocante ao pacto federativo, por meio de "um regime de decisões nacionalmente centralizadas e de execuções de políticas sociais subnacionalmente desconcentradas em que se percebe uma situação de competitividade recíproca (guerra fiscal) entre os subnacionais”.

Tal cenário contribuiu, sobremaneira, para a desarticulação de experiências e projetos em andamento e para a adoção de medidas ligadas às políticas federais para a educação básica, em função da necessidade dos sistemas e escolas buscarem fontes complementares de recursos. Tal adesão, contudo, não provocou, necessariamente, a mudança da cultura institucional dos sistemas e das escolas. Em muitos casos, resultou em ajustes e arranjos funcionais dos processos em curso nesses espaços, alterando, por vezes, a lógica e a natureza das escolas e, em alguns casos, a sua concepção pedagógica, a fim de cumprir obrigações "contratuais" com o governo federal no âmbito da prestação de contas. 
Essa lógica e dinâmica política é, ainda, uma realidade no cenário educacional brasileiro, na medida em que não se elaborou a lei complementar que definiria o regime de colaboração recíproca entre os entes federados, manteve-se a indução de políticas, por meio de financiamento de programas e açôes priorizadas pela esfera federal, e não se adotou o Plano Nacional de Educação (PNE) como referênciabase para as políticas educacionais. Adicione-se a isso, mais recentemente, a apresentação pelo MEC de um Plano de Desenvolvimento da Educação (PDE), que não contou, na sua elaboração, com a participação efetiva de setores organizados da sociedade brasileira, de representantes dos sistemas de ensino e de setores do próprio Ministério. O PDE apresenta indicaçóes de grandes e importantes açóes direcionadas à educação nacional. No entanto, não está balizado por fundamentação técnico-pedagógica suficiente e carece de articulação efetiva entre os diferentes programas e ações em desenvolvimento pelo próprio MEC e as políticas propostas. Tal constatação revela a necessidade de planejamento sistemático, que, após avaliar o conjunto de açóes, programas e planos em desenvolvimento, contribua para o estabelecimento de políticas que garantam organicidade entre as políticas, entre os diferentes órgãos do MEC, sistemas de ensino e escola e, ainda, a necessária mediação entre o Estado, demandas sociais e o setor produtivo, em um cenário historicamente demarcado pela fragmentação e/ou superposição de açôes e programas, o que resulta na centralização das políticas de organização e gestão da educação básica no país. Trata-se de um cenário ambíguo, no qual um conjunto de programas parece avançar na direção de políticas com caráter inclusivo e democrático, enquanto, de outro lado, prevalece a ênfase gerencial, com forte viés tecnicista e produtivista, que vislumbra nos testes estandardizados a naturalização do cenário desigual em que se dá a educação brasileira.

Os programas federais de educação básica, atravessados por concepções distintas e até antagônicas, realçam o cenário contraditório das ações governamentais. Tal perspectiva enseja a necessidade de maior organicidade entre as políticas, açōes e programas.

$\mathrm{Na}$ década atual, várias políticas, programas e açōes foram realizados pelo governo federal, após a aprovação de um PNE sob a ótica gerencial e patrimonial. É oportuno destacar, contudo, que grande parte das políticas educacionais foi reorientada, a partir de 2003, 
implicando alterações nos marcos regulatórios vigentes para a educação básica e superior. Nesse sentido, o governo federal pautou sua atuação pelo princípio da defesa da educação de qualidade, a partir do binômio inclusão e democratização. Algumas ações mereceram particular destaque, como a ampliação do ensino fundamental de oito para nove anos, as políticas de ação afirmativa e, de modo estrutural, a criação do Fundo de Manutenção e Desenvolvimento da Educação Básica e de Valorização dos Profissionais da Educação (FUndeb).

Atualmente, articulam-se esforços dos entes federados para garantir a regulamentação do FUNDEB, ${ }^{7}$ de natureza contábil, cujo desenho pode representar um avanço na dinâmica e lógica do financiamento da educação básica nacional, sobretudo quanto à sua caracterização (direcionado à educação infantil, ensino fundamental e médio).

Aliados ao redimensionamento do financiamento da educação básica, destacam-se os planos de educação, notadamente o PNE, os Planos Estaduais de Educação (PEE) e os Planos Municipais de Educação (PME). Se entendidos como planos de Estado, estes deveriam implicar redimensionamento das políticas e gestão e, fundamentalmente, da lógica de financiamento e, portanto, do orçamento público. Tal dinâmica encontra-se desarticulada e associada à lógica de desconcentração que tem marcado a educação nacional. Merece ser destacado, contudo, o esforço desenvolvido para estimular a formação de conselhos, bem como a sua capacitação. ${ }^{8}$

Quanto ao PNE, é importante ressaltar que, aliado às metas vetadas, ele não foi integrado efetivamente ao processo de elaboração do Plano Plurianual (PPA) e suas revisões. Considerando que o PPA é um instrumento fundamental do orçamento público, juntamente com a Lei de Diretrizes Orçamentárias e a Lei Orçamentária Anual, esse processo não resultou em organicidade orçamentária que viesse dar efetividade às metas do PNE.

Apesar desse cenário de mudanças na área da gestão educacional, vários programas foram mantidos no formato original, destacando-se o Plano de Desenvolvimento da Escola (PDE). Por outro lado, novos programas foram implantados, a fim de contribuir com os processos de democratização da escola, com destaque para o Programa Nacional de Fortalecimento de Conselhos Escolares. 
Plano e programas federais em andamento na área de gestão escolar

Como afirmamos anteriormente, na área de gestão escolar, muitos programas foram implantados, objetivando contribuir para o processo de democratização da escola. No campo da gestão, três programas traduzem esse movimento ambíguo: O PDE, PDDE e o Programa Nacional de Fortalecimento de Conselhos Escolares.

Sem pormenorizar os referidos programas, indicarei a seguir algumas características, sobretudo no que concerne à concepção e lógica político-pedagógica que os caracterizam.

\section{a) O Plano de Desenvolvimento da Escola (PDE) e o Fundo de Forta- lecimento da Escola (fundesCOlA)}

O FUNDESCOLA é um dos espaços de desenvolvimento de programas do Ministério da Educação, por meio de parcerias com as secretarias estaduais e municipais de educação das regiôes Norte, Nordeste e Centro-Oeste, e tem por objetivo promover um conjunto de açóes voltadas para as escolas do ensino fundamental.

O FUNDESCOLA, por meio de processos formativos e de apoio à gestão educacional, tem como meta a busca da eficácia, eficiência e equiidade no ensino fundamental público, ao focalizar o ensino-aprendizagem e as práticas de gestão das escolas e secretarias de educação. As estratégias descritas no PDE enfatizam o desenvolvimento de açōes para aperfeiçoar o trabalho, elevar o grau de conhecimento e o compromisso de diretores, professores e outros funcionários da escola com os resultados educacionais. $\mathrm{Na}$ área de gestão, o PDE é um dos programas centrais do FUNDESCOLA, dada a sua abrangência e inserção nas três regiōes. A esse respeito, Oliveira, Fonseca e Toschi (2004a, p. 29) afirmam que

(...) a proposta concebida no âmbito do FUNDESCOLA enfatiza a "gestão democrática" centrada numa concepção gerencialista e eficientista, como instrumento legal para organização do trabalho escolar. A autonomia escolar é garantida por um fundo repassado à escola, com vistas a estimular o quadro administrativo a tomar decisões que afetem materialmente a escola e a responsabilizar-se pelos resultados de suas decisóes.

Nesse cenário, os autores mencionados (2004b, p. 40) afirmam que o 
PDE é entendido como o carro-chefe do FUNDESCOLA, uma vez que assinala uma ênfase na "escola com foco no aluno". Nesse processo, a escola é considerada a responsável pela melhoria da qualidade de ensino, e o projeto visa modernizar a gestão e fortalecer a autonomia da escola, segundo um processo de planejamento estratégico coordenado pela liderança da escola e elaborado de maneira participativa.

Com relação ao PDE, Freitas et al. (2004, p. 71) afirmam que este plano estrutura-se por meio de "uma nova cultura organizacional firmada sobre princípios de gestão estratégica e do controle da qualidade total, orientada pela e para a racionalização, a eficiência e a eficácia”. Desse modo, ideologicamente, o PDE, desde a sua concepção, "busca criar o consenso em torno da idéia de que a melhoria da educação estaria na adoção dos parâmetros de mercado, com a aplicação de estratégias da empresa privada na gestão da escola pública”. Tal concepção alicerça-se numa ressignificação da gestão democrática e da participação, entendidas a partir da criação de canais de efetiva participação e decisão coletivas, tendo por norte a educação como um bem público.

Outro ponto fundamental a ser destacado articula-se à concepção restrita de autonomia (restrita à dimensão financeira) e ao caráter diretivo e centralizador do $\mathrm{PDE}$, num cenário em que os profissionais da educação e alguns sistemas de ensino envidavam esforços no sentido de implementar, com base na legislação em vigor, projetos políticopedagógicos cujo norte se contrapunha à concepção gerencialista presente no PDE. Oliveira, Fonseca e Toschi (2004c, p. 198), ao avaliarem o PDE e a gestão pedagógica, físico-financeira e de materiais da escola, adjetivaram a proposição e materialização desse plano por meio da diretividade, burocratização e controle do trabalho escolar e destacaram, ainda, que o

PDE favoreceu a proliferação de empresas de consultoria e de capacitação docente por meio de cursos previamente montados por elas. Essas empresas fazem, portanto, o trabalho de agenciamento e de planejamento, cabendo à escola a prerrogativa de escolher os cursos com base na oferta das empresas.

Essas pesquisas ressaltam a lógica do plano e seu distanciamento dos marcos legais que preconizam o princípio da gestão democrática e dos processos de participação subjacentes a esta, bem como a importância da efetivação de projeto pedagógico pelas unidades escolares, 
com base na regulamentação da gestão democrática pelos sistemas de ensino.

Apesar do distanciamento inicial da Secretaria de Ensino Fundamental (cuja denominação atual é Secretaria de Educação Básica SEB) do MEC, o PDE, por meio do FUndescola, buscou, a partir de 2003, vincular-se a esta Secretaria, dada a singularidade das ações desenvolvidas. A esse respeito, são importantes os movimentos direcionados a uma articulação orgânica entre a Secretaria e o FUNDESCOLA. Por outro lado, em 2004, foi materializada a transferência da gestão integral do FUNDESCOLA para o FNDE (Dourado, 2004, p. 10). Tal mudança contribui, sobremaneira, para o crescente divórcio entre as ações do Fundo, entre elas o PDE, e as ações e programas da SEB, resultando, em muitos casos, na sobreposição de ações e em planos e programas com concepções político-pedagógicas distintas no âmbito do governo federal.

Assim, é fundamental registrar que o FUNDESCOLA desenvolve ações, em especial na área de gestão, sem clara interlocução com as demais políticas das Secretarias do MEC. O PDE, nesse cenário, tem foco e ação político-pedagógica baseados em concepção gerencial, cujo processo ignora o esforço desenvolvido pelo MEC no apoio técnico e financeiro para a democratização da gestão escolar.

\section{b) O Programa Dinheiro Direto na Escola (PDDE)}

O PDDE consiste no repasse anual de recursos por meio do FNDE às escolas públicas do ensino fundamental estaduais, municipais e do Distrito Federal e às do ensino especial mantidas por organizações nãogovernamentais (ONGs), desde que registradas no Conselho Nacional de Assistência Social (CNAS).

Os recursos, oriundos predominantemente do "salário-educação", são destinados à aquisição de material permanente e de consumo necessários ao funcionamento da escola; à manutenção, conservação e pequenos reparos da unidade escolar; à capacitação e ao aperfeiçoamento de profissionais da educação; à avaliação de aprendizagem; à implementação de projeto pedagógico; e ao desenvolvimento de atividades educacionais. Um dos limites interpostos ao Programa refere-se à estruturação de unidades executoras nas unidades escolares, o que, 
em muitos casos, tem resultado na instituição de entes privados como gestores de recursos das escolas públicas, em detrimento de outros atores, como conselhos escolares, fortemente referendados por outro programa da SEB/MEC.

Em pesquisa realizada em cinco estados (São Paulo, Rio Grande do Sul, Mato Grosso do Sul, Pará e Piauí), buscando inventariar e analisar o processo de implementação do PDDE e suas conseqüências para a gestão dos sistemas, Adrião e Peroni (2007, p. 254-267) destacam as concepções norteadoras desse Programa e o seu papel na redefinição da regulação estatal, por meio da criação de unidades executoras. As autoras afirmam (p. 258) que, "Declaradamente, o Programa opta pela criação de UEX de natureza privada como mecanismo para assegurar maior flexibilidade na gestão dos recursos repassados e ampliar a participação da comunidade escolar nessa mesma gestão". Ressaltam, ainda, a abrangência do Programa, ao mesmo tempo em que destacam (p. 259) que "a generalização das UEX para as diferentes redes e sistemas de ensino, de certa maneira, padronizou um formato institucional que delega a responsabilidade sobre a gestão dos recursos públicos descentralizados para uma instituição de natureza privada”.

Nesse cenário, o referido Programa vai ocupando papel estratégico nas escolas, na medida em que, em muitos casos, acaba por redirecionar espaços de participação e deliberação, como os conselhos escolares, em unidade executora. A esse respeito, Adrião e Peroni, ao analisarem os casos da rede municipal de Porto Alegre e das redes estaduais de Rio Grande do Sul e Mato Grosso do Sul, afirmam que

(...) a proposta de transformação dos Conselhos Escolares em unidades executoras assumiu um caráter de disputa política entre diferentes segmentos da educação. O dilema vivido pelos sistemas relacionava-se à opção em alterar a natureza jurídica dos Conselhos Escolares, transformando-os em uma unidade executora, cuja conseqüência seria a instalação de uma instituição de direito privado na esfera da gestão da escola ou, de outro modo, o fortalecimento do Círculo de Pais e Mestres (СРM), estrutura análoga às Associações de Pais e Mestres (APM), tradicionalmente menos democrática e, em muitos casos, não subordinada ao controle do colegiado gestor. (2007, p. 260)

As autoras alertam, ainda, para o fato de que essa indução de políticas de gestão, cuja ênfase recai sobre a dimensão técnico-operacional, possa 
(...) redundar em limites para a própria democratização da gestão. No caso em que os Conselhos, recém-criados, nascem já crivados pela lógica da UEX, erigida a partir da ambigüidade que a caracteriza (entidade de natureza privada articulada ao setor público) e da função que lhe é prioritária - captar recursos privados e gerir recursos públicos descentralizados -, no funcionamento desses colegiados há uma tendência de secundarizar o exercício das práticas democráticas nas decisões. (Adrião \& Peroni, 2007, p. 260)

Sem descurar da importância do referido Programa no que concerne à descentralização de recursos financeiros para a escola, em cenário de nítida escassez de recursos, a análise do PDDE demonstra que sua implementação tem resultado no desrespeito ao pacto federativo, na medida em que o Programa atropela os sistemas de ensino ao redefinir novos formatos de gestão para as escolas públicas, por meio do "estabelecimento de relações diretas entre as escolas beneficiadas e o FNDE, sem a intervenção de instâncias governamentais locais na definição e execução dos gastos" (idem, ibid., p. 264).

Outro aspecto ressaltado pelas autoras (p. 265) refere-se à pequena participação da comunidade escolar, pois "o fato do Programa não pressupor para a sua realização a efetiva democratização da gestão da esfera pública fez com que, em muitos casos, fosse pequena a desejada participação da comunidade na operação de recursos repassados".

Todos esses indicadores demonstram que as bases político-pedagógicas do PDDE, a despeito de possibilitar às unidades escolares a gestão de pequenos recursos, por meio de entidade privada, não contribuíram efetivamente para a democratização dos processos de deliberação coletiva e, ainda, restringiram a autonomia à gestão financeira da escola.

\section{c) Programa de Fortalecimento de Conselhos Escolares}

Esse Programa tem por objetivo contribuir com a discussão sobre a importância de conselhos escolares nas instituições e visa, ainda, ao fortalecimento dos conselhos existentes. Os conselhos escolares configuram-se, historicamente, como espaços de participação de professores, funcionários, pais, alunos, diretores e comunidade nas unidades escolares. Em alguns casos, constituem-se em espaços coletivos de deliberação, assumindo, desse modo, o papel de órgão co-responsável pela gestão administrativa e pedagógica das escolas e, em outros, em razão 
de sua atuação restrita à aprovação da prestação de contas e medidas disciplinares, em determinadas situaçôes, foram transformados em unidades executoras em razão do PDDE.

O Programa foi criado, portanto, pela Secretaria de Educação Básica do Ministério da Educação, mediante a Portaria Ministerial n. $2.896 / 2004$. Visa à implantação e ao fortalecimento de conselhos escolares nas escolas públicas de educação básica nas cinco regiões do país, envolvendo os sistemas de ensino públicos estaduais e municipais, por meio de sua adesão à sistemática de apoio técnico, pedagógico e financeiro do Ministério da Educação.

De acordo com a mesma Portaria Ministerial, tem por objetivos: I - Ampliar a participação das comunidades escolar e local na gestão administrativa, financeira e pedagógica das escolas públicas; II - apoiar a implantação e o fortalecimento de conselhos escolares; III - instituir políticas de indução para implantação de conselhos escolares; IV - promover, em parceria com os sistemas de ensino, a capacitação de conselheiros escolares, utilizando inclusive metodologias de educação a distância; V - estimular a integração entre os conselhos escolares; VI - apoiar os conselhos escolares na construção coletiva de um projeto educacional no âmbito da escola, em consonância com o processo de democratização da sociedade; e VII - promover a cultura do monitoramento e avaliação no âmbito das escolas para a garantia da qualidade da educação.

A referida Portaria define, ainda, que a execução do Programa será de responsabilidade da SEB e que esta deverá contar com a participação de órgãos e organismos nacionais e internacionais em um trabalho integrado de parcerias para a consecução dos objetivos. Nesse sentido, vale ressaltar que a efetivação dos objetivos preconizados envolve, fundamentalmente, a adesão ao Programa pelos estados e municípios.

O Programa estruturou-se a partir de processos de formação continuada dos diversos segmentos que compõem a unidade escolar, por meio de duas frentes articuladas - de um lado, pela realização de seminários estaduais de formação, seminário internacional de gestão, seminários municipais e, de outro, pela oferta de curso de formação pela modalidade de educação a distancia.

Apresenta-se organizado a partir de cinco eixos iniciais - conselhos escolares, democratização da escola e construção da cidadania; conselho escolar e o respeito e valorização do saber e da cultura do 
estudante e da comunidade; conselho escolar e o aproveitamento significativo do tempo pedagógico; conselho escolar e a aprendizagem na escola; conselho escolar, gestão democrática da educação e escolha do diretor. Em seguida, o Programa ampliou tais eixos com as seguintes temáticas: conselho escolar como espaço de formação humana; conselho escolar e o financiamento da educação; conselho escolar e a educação no campo; conselho escolar e a relação entre a escola e o desenvolvimento com igualdade social.

Além desses núcleos temáticos, contemplou-se a discussão sobre os indicadores de qualidade da educação e os conselhos escolares como estratégia de gestão democrática da educação pública. Como é possível evidenciar, tais temáticas abrangem importantes questões em debate nas unidades escolares.

Em que pese a centralidade conferida a esse Programa, é fundamental destacar que o eixo da gestão democrática e da efetiva participação, bem como a centralidade conferida a órgãos de deliberação coletiva como os conselhos escolares, encontra limites em outros programas do próprio governo federal já analisados.

Os três programas e os limites às políticas e gestão da educação no Brasil

Ao longo da implantação dos três programas indicados, vários questionamentos se desdobram sobre a lógica e a concepção políticopedagógica subjacente a eles. Nessa direção, ganha relevância, de um lado, o descompasso entre o Programa Nacional de Fortalecimento dos Conselhos Escolares, em tese centrado em premissa articulada a instâncias de participação e deliberação coletivas, e, de outro, o Plano de Desenvolvimento da Escola ( $\mathrm{PDE}$ ), cuja lógica e dinâmica pedagógica enfatiza, sobretudo, a organização gerencial dos processos de gestão, secundarizando a efetiva participação da comunidade local e escolar nos destinos da escola e, ainda, o PDDE, com o objetivo de agilizar a assistência financeira do FNDE aos sistemas públicos de ensino, objetivando garantir o cumprimento do artigo 211, da Constituição Federal de 1988, no que concerne ao apoio técnico e financeiro da União.

Essa constatação também nos revela a falta de organicidade entre as políticas de gestão e organização das unidades escolares desenvolvidas 
pelo MEC, resultando em programas e ações cujo escopo político-pedagógico encontra-se, contraditoriamente, estruturado por concepçôes distintas. De um lado, a centralidade conferida à gestão democrática e, de outro, a concepção gerencial como norte pedagógico.

O Programa Nacional de Fortalecimento de Conselhos Escolares constitui-se em avanço importante frente ao pragmatismo das políticas do governo para a gestão escolar. Ao mesmo tempo, ao disputar espaço com programas financiados pelo Banco Mundial, estruturados sob forte égide gerencial, pode vir a ser secundarizado nas políticas e gestão das escolas no país. Tal ambigüidade revela a dificuldade de se efetivar políticas, em âmbito nacional, sem a garantia de relação com os sistemas de ensino e com os profissionais da educação que aí atuam, bem como a adoção de políticas preconizadas por agências e organismos internacionais, sem a devida mediação com o cenário nacional. Tal dinâmica tem resultado em forte descompasso entre a proposição e a materialização das políticas, contribuindo para

(...) um processo de sedimentação normativa que resulta da sobreposição de novas regras, orientações e reformas (produzidas numa volúpia de transformação permanente que raramente ultrapassa a superfície do sistema), às práticas e estruturas antigas que, na maior parte dos casos, acabam por subsistir, ainda que "travestidas" de uma pretensa modernidade. (Barroso, 2006b, p. 53)

Essa discussão nos remete à chamada descentralização da educação brasileira e aos problemas daí decorrentes, destacando-se a municipalização do ensino. ${ }^{9}$ Assim, diversas análises realçam que, no Brasil, houve a desconcentração de ações educacionais de forma muito mais efetiva do que a descentralização garantidora de autonomia aos entes federados. Ou seja, o que ocorre é a transferência de competências de um ente federado para outro, resultando na manutenção de açôes pontuais e focalizadas de apoio técnico e financeiro, em detrimento de ampla política de planejamento, financiamento e gestão da educação básica. A despeito disso, predominam, no cenário educacional, vários processos de regulação que permeiam o cotidiano dos sistemas de ensino e das escolas públicas, sob a hegemonia da União, por meio da indução de políticas de financiamento de ações e programas governamentais. Paralelamente à regulação nacional, assiste-se, portanto, ao desenvolvimento de processos formais e informais de regulação no nível 
dos territórios e das organizações (micro-regulação local). A esse respeito, ver Barroso (2006b, p. 59).

Pensar as políticas e a gestão da educação no Brasil, sobretudo a partir da defesa de um padrão de qualidade socialmente referenciada, nos insere no desafio de pensar a lógica centralizada e autoritária que tem permeado as políticas educacionais para todos os níveis de ensino, particularmente para a educação básica. Esse nível de ensino, composto pela educação infantil, ensino fundamental e médio, possui estruturação complexa e heterogênea, fortemente balizada por múltiplas formas de regulação e controle, incluindo a ação do MEC, dos sistemas de ensino e das escolas (caracterizadas como espaço de regulação importante na materialização das políticas).

Ao analisar as convergências e divergências nos modos de regulação européia, Maroy (2006, p. 230) afirma que

Os sistemas educativos europeus estão sujeitos a pressões externas de ordem econômica, social e política, assim como as evoluçôes internas que conduzem a novos modos de regulação das organizações escolares e às práticas do trabalho docente.

A despeito das diferenças na forma de organização dos sistemas de ensino, o autor identifica convergências nas políticas educativas, malgrado as diferenças de intensidade, de um país para outro. Isso nos permite detectar pontos comuns à realidade brasileira, o que, certamente, traduz a eficácia das pressões externas no campo educacional, sobretudo na proposição de novas políticas, quer sejam em países centrais, quer sejam em países periféricos como o Brasil.

Dentre os pontos mencionados por Maroy (op. cit., p. 231), destacamos: tendência para crescente autonomia na gestão das escolas e, em simultâneo, aumento dos mecanismos de controle por um conjunto de meios (avaliação, modelos e monitorização e supervisão de práticas...); procura de equilíbrio entre centralização e descentralização; crescimento, em diferentes níveis, da avaliação externa: avaliação do sistema no seu todo, das instâncias intermediárias ou regionais e dos organismos locais; e políticas de diversificação da oferta escolar. Segundo o autor, essas convergências, aliadas à crescente "hibridização" dos níveis institucionais simbólicos ou materiais da realidade de cada país, resultam, por vezes, em contradições no bojo das políticas adotadas. Ele afirma, ainda, que o fenômeno da "hibridização" "prende-se com a mistura 
de várias lógicas e orientações dentro da mesma política, o que, por vezes, se poderá traduzir em algumas contradições" (ibid., p. 233). A análise permite apreender que esse cenário poderá contribuir para mais fragmentação das políticas nos sistemas e unidades escolares. A realidade do sistema educacional brasileiro indica a superposição e um alto grau de fragmentação de ações e programas e, conseqüentemente, das políticas educacionais que os fundamentam.

Por essa razão, e devido aos contornos assumidos pelas políticas em curso, a análise das políticas educacionais e de sua inflexão na área de gestão implica, certamente, rediscutir a regulamentação do regime de colaboração entre os entes federados, a fim de estabelecer novas bases de financiamento à educação básica e o incremento do percentual de recursos destinados a esse nível de ensino.

Políticas e gestão da educação básica: democratizando o acesso e a permanência com qualidade

Algumas políticas, programas e ações têm se desencadeado nos âmbitos federal, estadual e municipal, a fim de contribuir para a ampliação das oportunidades educacionais na educação básica, tarefa constitucionalmente de competência direta dos estados, Distrito Federal e municípios. A iniciativa da União, por meio da indução do financiamento de ações, programas e políticas, nem sempre tem se realizado de modo orgânico, na medida em que se caracteriza pela superposição e pela ingerência direta nas escolas vinculadas aos sistemas de ensino, entre outros. Nesse cenário, assiste-se a um discurso marcadamente voltado à descentralização do ensino, por meio do regime de colaboração entre os entes federados, e à proposição de políticas centralizadas no âmbito de programas e ações do MEC, nem sempre articuladas e cuja adesão por estados e municípios se efetiva, historicamente, sem clara conexão com prioridades estabelecidas pelos respectivos sistemas de ensino.

Dessa forma, assegurar condiçôes políticas e de gestão para o envolvimento e a participação da sociedade civil na formulação, implementação das ações e programas de universalização da educação básica, bem como a melhoria da educação nos diferentes níveis e modalidades, é tarefa dos poderes públicos. No Brasil, dada a natureza 
patrimonial do Estado, muito há que ser feito, a fim de garantir a participação da sociedade civil nas políticas públicas, especialmente na educação.

Essas constataçôes contribuem para a compreensão de que a democratização do ensino não se dá somente pela garantia do acesso, requerendo sua oferta com qualidade social, para otimizar a permanência dos estudantes e, desse modo, contribuir para a melhoria dos processos formativos e a participação cidadã.

Todas essas questões se articulam às condições objetivas da população, em um país historicamente demarcado por forte desigualdade social, revelada nos indicadores sociais preocupantes e que, nesse sentido, carece de amplas políticas públicas, incluindo a garantia de otimização nas políticas de acesso, permanência e gestão, com qualidade social, na educação básica.

Políticas e gestão para uma educação básica de qualidade: desafio nacional

O investimento em educação básica, tendo a qualidade como parâmetro de suas diretrizes, metas e ações e conferindo a essa qualidade uma dimensão sócio-histórica e, portanto, inclusiva, é um grande desafio para o país, em especial para as políticas e gestão desse nível de ensino. Pensar a qualidade social da educação implica assegurar um processo pedagógico pautado pela eficiência, eficácia e efetividade social, de modo a contribuir com a melhoria da aprendizagem dos educandos, em articulação à melhoria das condições de vida e de formação da população.

A busca por melhoria da qualidade da educação exige medidas não só no campo do ingresso e da permanência, mas requer ações que possam reverter a situação de baixa qualidade da aprendizagem na educação básica, o que pressupõe, por um lado, identificar os condicionantes da política de gestão e, por outro, refletir sobre a construção de estratégias de mudança do quadro atual.

O conceito de qualidade, nessa perspectiva, não pode ser reduzido a rendimento escolar, nem tomado como referência para o estabelecimento de mero ranking entre as instituiçóes de ensino. Assim, uma educação com qualidade social é caracterizada por um conjunto 
de fatores intra e extra-escolares que se referem às condições de vida dos alunos e de suas famílias, ao seu contexto social, cultural e econômico e à própria escola - professores, diretores, projeto pedagógico, recursos, instalaçôes, estrutura organizacional, ambiente escolar e relaçōes intersubjetivas no cotidiano escolar. Segundo Dourado, Oliveira e Santos (2007, p. 9),

(...) a qualidade da educação é um fenômeno complexo, abrangente, e que envolve múltiplas dimensões, não podendo ser apreendido apenas por um reconhecimento de variedade e das quantidades mínimas de insumos considerados indispensáveis ao desenvolvimento do processo ensino-aprendizagem e muito menos sem tais insumos (...). Desse modo, a qualidade da educação é definida envolvendo a relação entre os recursos materiais e humanos, bem como a partir da relação que ocorre na escola e na sala de aula (...).

É em consonância com essa perspectiva e no intuito de melhorar a qualidade da educação brasileira que devem se situar as açōes, mediadas por efetiva regulamentação do regime de colaboração entre a União, estados, Distrito Federal e municípios, objetivando, de fato, assegurar um padrão de acesso, permanência e gestão na educação básica, pautado por políticas e açôes que promovam a educação democrática e de qualidade social para todos.

\section{Recebido e aprovado em julho de 2007.}

\section{Notas}

1. A esse respeito, cf. Dourado e Costa (1988); Mendonça (2000); Gracindo e Wittiman (2001); Ferreira (2003, 2006, 2006a); Oliveira (2000, 2000a); Dourado (2006a, 2006b, 2006c, 2006d); Sander (1984, 2007); Souza (2006); Cury (2002); Ferreira (2003, 2006a, 2006b); Dourado e Paro (2001); Félix (1984); Mendonça (2000); Oliveira (1997, 2003); Paro (1998); Luce e Medeiros (2006), entre outros.

2. A discussão sobre políticas e gestão da educação tem sido fortemente marcada pelos novos formatos organizativos decorrentes da estruturação de mercados comuns, o que, entre outros, tem resultado em investigações sobre os impactos, a natureza, processos regulatórios e marcos de tais mercados. Nessa direção, merece destaque estudos desenvolvidos por Barroso (2006a e 2006b). Destacam-se, ainda, outros estudos sobre a temática desenvolvidos por Barroso (2003), Maroy (2006) e Lima (1998).

3. A esse respeito, ver Frigotto (1995).

4. Paro (1998) e Félix (1984) descortinam análises sobre a especificidade da gestão educacional e escolar, contrapondo-se à mera apreensão da lógica empresarial no campo educativo.

Educ. Soc., Campinas, vol. 28, n. 100 - Especial, p. 921-946, out. 2007 
Políticas e gestão da educação básica no Brasil: limites e perspectivas

5. A respeito dos embates relativos à formação docente no Brasil, ver Freitas (2002) e Aguiar (2006).

6. Após a aprovação da CF-1988, três alterações nos textos legais são de grande importância para a área educacional: a aprovação da Lei de Diretrizes e Bases da Educação Nacional (LDB - Lei n. 9.394/96); a aprovação da Emenda Constitucional que instituiu o Fundo de Manutenção e Desenvolvimento do Ensino Fundamental (FUNDEF) e do Plano Nacional de Educação (PNE - Lei n. 10.172/2001).

7. O FUNDEB coloca-se, desse modo, como importante espaço para a rediscussão da relação entre os entes federados. Sua regulamentação pode contribuir para o cumprimento de dispositivo constitucional, na medida em que incrementa a dinâmica da subvinculação de recursos à educação, entre outros, por: sua abrangência, ao financiar toda a educação básica; definir que leis complementares deverão fixar as normas para a cooperação entre a União e os estados, o Distrito Federal e os municípios; entre outros. É importante não perder de vista, por outro lado, que várias críticas referentes aos limites da política de financiamento por meio do FUndef (Pinto, 2002; Arelaro, 1999; Gouveia et al., 2006) servem de base para o FUNDEB. Merecem ser ressaltados, contudo, os limites do FUNDEB, no que concerne, entre outros: à lógica desigual e diversificada do sistema educacional brasileiro, à enorme tarefa reservada aos municípios, sobretudo quanto à educação infantil, à definição precária do valor-referência para o custo aluno/qualidade, para as diversas etapas e modalidades da educação básica, à participação efetiva da União no repasse de recursos.

8. O MEC vem desenvolvendo o Programa Nacional de Capacitação de Conselheiros Municipais de Educação, com vistas a contribuir para a implementação dos conselhos como instâncias fundamentais no processo de consolidação da ação dos municípios na gestão educacional. Esse programa tem como metas a criação de novos conselhos, a integração dos conselhos já existentes e a formação de pelo menos dois conselheiros por município.

9. A esse respeito, ver Costa (1999), Gil e Arelaro (2004), Oliveira et al. (1999), entre outros.

\section{Referências bibliográficas}

ADRIÃO, T.; PERONI, V. Implicações do Programa Dinheiro Direto na Escola para a gestão da escola pública. Educação \& Sociedade, Campinas, v. 28, n. 98, p.253-267, jan./abr. 2007.

AGUIAR, M.A.S. A formação dos profissionais da educação básica no curso de Pedagogia. In: Ferreira, N.S.C.; Aguiar, M.A.S. (Org.). Para onde vão a orientação e a supervisão educacional? 2. ed. Campinas: Papirus, 2006. p. 107-122.

AZEVEDO, J.M.L. Implicaçôes da nova lógica de ação do Estado para a educação municipal. Educação \& Sociedade, Campinas, v. 23, n. 80, p. 49-71, set. 2002.

BARROSO, J. A investigação sobre a regulação das políticas públicas de educação em Portugal. In: BarRoso, J. (Org.). A regulação das 
políticas públicas de educação: espaços, dinâmicas e atores. Lisboa: Educa, 2006a. p. 9-39.

BARROSO, J. O Estado e a educação: a regulação transnacional, a regulação nacional e a regulação local. In: BARROSO, J. (Org.). A regulação das políticas públicas de educação: espaços, dinâmicas e atores. Lisboa: Educa, 2006b. p. 41-70.

BRASIL. Constituição (1988). Constituição da República Federativa do Brasil. 25. ed. São Paulo: Saraiva, 2000.

BRASIL. Lei n. 9.394/96, de 20 de dezembro 1996. Estabelece as diretrizes e bases da educação nacional. Diário Oficial da União, Brasília, DF, 23 dez. 1996. p. 27894.

BRASIL. Lei n. 10.172, de 9 janeiro de 2001. Institui o Plano Nacional de Educação e dá outras providências. Diário Oficial da União, Brasília, DF, 10 jan. 2001.

BRASIL. Portaria Ministério da Educação n. 2.896, de 17 de setembro de 2004. Cria o Programa Nacional de Fortalecimento de Conselhos Escolares. Diário Oficial da União, Brasília, DF, n. 180. Seção 2, p. 7.

COSTA, V.L.C. (Org.). Descentralização da educação: novas formas de coordenação e financiamento. São Paulo: FUNDAP; Cortez, 1999.

CURY, C.R.J. A educação básica no Brasil. Educação \& Sociedade, Campinas, v. 23, n. 80, p. 169-201, set. 2002.

DOURADO, L.F. Relatório de gestão da diretoria geral do FUNDESCOLA. Brasília, DF, 2004. 50p. (mimeo).

DOURADO, L.F. Financiamento da educação no Brasil: aportes teóricos e a construção de uma rede de pesquisadores. In: GouveiA, A.B.; SouzA, A.R.; Tavares, T.M. (Org.). Conversas sobre financiamento da educação no Brasil. Curitiba: UfPR, 2006a. p. 27-40.

DOURADO, L.F. Plano Nacional de Educação: avaliações e retomada do protagonismo da sociedade civil organizada na luta pela educação. In: Ferreira, N.S.C. (Org.). Políticas públicas e gestão da educação: polêmicas, fundamentos e análises. Brasília, DF: Liber Livro, 2006b. p. 21-50. 
DOURADO, L.F. A escolha de dirigentes escolares: políticas e gestão da educação no Brasil. In: Ferreira, N.S.C. (Org.). Gestão democrática da educação: atuais tendências, novos desafios. 5. ed. São Paulo: Cortez, 2006c. p. 77-95.

DOURADO, L.F. O público e o privado na agenda educacional brasileira. In: Ferreira, N.S.C.; Aguiar, M.A.S. (Org.). Gestão da educação: impasses, perspectivas e compromissos. São Paulo: Cortez, 2006d.

DOURADO, L.F.; COSTA, M. A escolha de dirigentes escolares no Brasil. Brasília: ANPAE, 1998.

DOURADO, L.F.; OLIVEIRA, J.F.; SANTOS, C.A. A qualidade da educação: conceitos e definições. Brasília, DF: INEP, 2007.

DOURADO, L.F.; PARO, V.H. Políticas educacionais e educação básica. São Paulo: Xamã, 2001.

FELIX, M.F.C. Administração escolar: um problema educativo ou empresarial? São Paulo: Cortez, 1984.

FERREIRA, N.S.C. A gestão da educação na sociedade mundializada. Rio de Janeiro: DP\&A, 2003. 237p.

FERREIRA, N.S.C. (Org.). Gestão democrática da educação: atuais tendências, novos desafios. 5. ed. São Paulo: Cortez, 2006a. 119p.

FERREIRA, N.S.C. (Org.). Políticas públicas e gestão da educação: polêmicas, fundamentos e análises. Brasília, DF: Liber Livro, 2006b.

FERREIRA, N.S.C.; AGUIAR, M.A.S. (Org.). Gestão da educação: impasses, perspectivas e compromissos. 5. ed. São Paulo: Cortez, 2006. $320 \mathrm{p}$.

FONSECA, M.; TOSCHI, M.S.; OLIVEIRA, J.F. Educação, gestão e organização escolar: concepções e tendências atuais. In: FONSECA, M.; Toschi, M.S.; Oliveira, J.F. (Org.). Escolas gerenciadas: planos de desenvolvimento e projetos político-pedagógicos em debate. Goiânia: UCG, 2004a. p. 21-34.

FONSECA, M.; TOSCHI, M.S.; OLIVEIRA, J.F. Programa fundescola: concepçóes, objetivos, componentes e abrangência; a perspectiva da melhoria da gestão do sistema e das escolas públicas. In: 
Fonseca, M.; Toschi, M.S.; Oliveira, J.F. (Org.). Escolas gerenciadas: planos de desenvolvimento e projetos político-pedagógicos em debate. Goiânia: UCG, 2004b. p. 35-53.

FONSECA, M.; TOSCHI, M.S.; OLIVEIRA, J.F. Escolas Gerenciadas: diretividade, burocratização e controle do trabalho escolar. In: FONSECA, M.; Toschi, M.S.; Oliveira, J.F. (Org.). Escolas gerenciadas: planos de desenvolvimento e projetos político-pedagógicos em debate. Goiânia: UCG, 2004c. p. 189-213.

FREITAS, H.C.L. Formação de professores no Brasil: 10 anos de embate entre projetos de formação. Educação \& Sociedade, Campinas, v. 23, n. 80, p.137-168, set. 2002.

FREITAS, H.C.L. et al. PDE: evidências no município de Dourados. In: Fonseca, M.; Toschi, M.S.; Oliveira, J.F. (Org.). Escolas gerenciadas: planos de desenvolvimento e projetos político-pedagógicos em debate. Goiânia: UCG, 2004. p. 55-80.

FRIGOTTO, G. Educação e crise do capitalismo real. São Paulo: Cortez, 1995.

GIL, J.; ARELARO, L.R.G. Contra a municipalização do ensino à brasileira. In: GIL, J. Educação municipal: experiências de políticas democrátivas. Ubatuba: Estação Palavra, 2004. 208p.

GOUVEIA, A.B.; SOUZA, A.R.; TAVARES, T.M. (Org.). Conversas sobre financiamento da educação no Brasil. Curitiba: UFPR, 2006.

GRACINDO, R.V.; WITTMANN, L.C. (Org.). O estado da arte em política e administração da educação no Brasil: 1991-1997. São Paulo: Autores Associados, 2001. 272p.

LIMA, L.C. A escola como organização e a participação na organização escolar. 2.ed. Braga: Instituto de Educação e Psicologia, 1998.

LUCE, M.B.; MEDEIROS, I.L.P. Gestão escolar democrática: concepções e vivências. Porto Alegre: UfrgS, 2006.

MAROY, C. Convergências e divergências dos modos de regulação numa perspectiva européia. In: BARroso, J. (Org.). A regulação das politicas públicas de educação: espaços, dinâmicas e atores. Lisboa: Educa, 2006. p. 227-244. 
MENDONÇA, E.F. A regra e o jogo: democracia e patrimonialismo na educação brasileira. Campinas: Lapplane; UNICAMP, 2000. 457p.

OLIVEIRA, C. et al. Municipalização do ensino no Brasil. Belo Horizonte: Autêntica, 1999. 124p.

OLIVEIRA, D.A. Gestão democrática da educação: desafios contemporâneos. 2. ed. Petrópolis: Vozes, 1997.

OLIVEIRA, D.A. Educação básica: gestão do trabalho e da pobreza. Petropólis: Vozes, 2000.

OLIVEIRA, D.A. A gestão democrática da educação no contexto da reforma do Estado. In: Ferreira, N.S.C.; Aguiar, M.A.S. (Org.). Gestão da educação: impasses, perspectivas e compromissos. São Paulo: Cortez, 2000a.

OLIVEIRA, R.P. Financiamento da educação no Brasil: um estado da arte provisório e algumas questões de pesquisa. In: GouveiA, A.B.; SouzA, A.R.; Tavares, T.M. (Org.). Conversas sobre financiamento da educação no Brasil. Curitiba: UfPR, 2006. p. 23-26.

PARO, V.H. Administração escolar: uma introdução crítica. 2. ed. São Paulo: Cortez; Autores Associados, 1988.

PINTO, J.M.R. Financiamento da educação no Brasil: um balanço do governo FHC (1995-2002). Educação \& Sociedade, Campinas, v. 23, n. 80 , p. 109-136, set. 2002.

SANDER, B. Gestão da educação na América Latina: construção e reconstrução do conhecimento. Campinas: Autores Associados, 1995.

SANDER, B. A pesquisa sobre política e gestão da educação no Brasil: temáticas, resultados e perspectivas. Trabalho apresentado no IV Congresso Luso Brasileiro de Política e Administração da Educação, 2007, Lisboa. 24p. (mimeo.).

SOUZA, A.R.D. Os caminhos da produção científica sobre a gestão escolar no Brasil. Revista Brasileira de Política e Administração da Educação, Porto Alegre, v. 22, n. 1, p. 13-39, jan./jun. 2006. 